Bajopas Volume 2 Number 2 December, 2009

$$
\begin{aligned}
& \text { Bayero Journal of Pure and Applied Sciences, 2(2): } 19 \text { - } 21 \\
& \text { Received: June, } 2009 \\
& \text { Accepted: July, } 2009
\end{aligned}
$$

\section{PROXIMATE, CAFFEINE AND TANNIN ANALYSES IN SOME BRANDS OF TEA CONSUMED IN KANO METROPOLIS, NIGERIA}

\author{
*M.I. Mohammed and M.A. Sulaiman \\ Department of Pure and Industrial Chemistry, Bayero University, P.M.B. 3011, Kano \\ *Correspondence author
}

\begin{abstract}
The determination of proximate, caffeine and tannin contents of five different (China, Kenya, India, Srilanka and Mambilla) tea leaves samples sold in Kano markets was conducted. The moisture content was generally high in all the tea samples and ranged from $5.6 \%$ in Mambila to $7.5 \%$ in India samples. Ash content was relatively low and ranged between $4.90 \%$ in Srilanka to $7.20 \%$ in Mambila and Kenya samples respectively. Crude fibre ranged from $14.00 \%$ in China to $18.82 \%$ in Srilanka samples, while ether extract content was within the range of $9.30 \%$ to $10.60 \%$ with the highest value found in Mambila sample and the least value in Kenya sample. Total nitrogen contents were low when compared with other workers' results and ranged from $0.88 \%$ in Kenya to $1.75 \%$ in Mambila and Srilanka samples respectively. Caffeine and tannin contents were found to be $1.4 \%$ in Kenya to $2.80 \%$ in China, $6.00 \%$ in Mambilla to $7.80 \%$ in India samples respectively.
\end{abstract}

Keywords: Proximate, Analysis, Caffeine, Tannin, Tea, Kano

\section{INTRODUCTION}

The origin of tea as a beverage is so old that it is lost in legend. Coffee is said to have been discovered by an Abyssinian goatherd who noticed an unusual friskiness in his goats when they consumed a certain little plant with red berries. He decided to try the berries himself and discovered coffee. The Arabs soon cultivated the coffee plant, and one of the earliest descriptions of its use is found in an Arabian medical book Crica 900 A.D. The great systematic botanist, Linnaeus, named the tree Coffea arabica (Sahito et al., 2005).

The active ingredient that makes tea and coffee valuable to humans is caffeine. Caffeine is an alkaloid, a class of naturally occurring compounds containing nitrogen and having the properties of an organic amine base (alkaline, hence, alkaloids). Tea and coffee are not the only plant sources of caffeine. Others include kola nuts, mate leaves, guarana seeds, and in small amount, cocoa beans. The pure alkaloid was first isolated from coffee in 1821 by the French chemist Pierre Jean Robiquet (Han et al., 2006).

Caffeine is a natural constituent of coffee, tea, and kola nuts (Kola nitida). Theophylline is found as a minor constituent of tea. The chief constituent of cocoa is theobromine. The amount of caffeine in tea varies from 2 to $5 \%$. In one analysis of black tea, the following compounds were found: caffeine, $2.5 \%$; theobromine, $0.17 \%$; beans can contain up to $5 \%$ by weight of caffeine, and cocoa contains around $5 \%$ theobromine (Han et al., 2006).

Caffeine has always been a controversial compound. Some religions forbid the use of beverages containing caffeine, which they consider an addictive drug. In fact, many people consider caffeine an addictive drug. Recently there has been concern because caffeine is structurally similar to the purine bases adenine and guanine, which are two of the five principal bases organisms use to form the nucleic acids DNA and RNA. It is feared that the substitution of caffeine for adenine or guanine in either of these genetically important substances could lead to chromosome defects (Han et al., 2006).

When any type of tea leaf is steeped in hot water it brews a "tart" (astringent) flavor that is characteristic of tannins. This is due to the catechins and other flavonoids. Tea "tannins" are chemically distinct from other types of plant tannins such as tannic acid and tea extracts have been reported to contain no tannic acid. Black tea and peppermint tisane are more inhibitory of iron than herb infusions like chammolie, vervain, lime flower and pennyroyal (Kumar et al., 2005).

Sahito et al. (2005) reported the contents of fifteen essential trace and toxic elements in some green tea samples and in their infusion. Karimi et al. (2008) worked on the concentrations and health risk of metals in tea samples marketed in Iran. Effects of tannase treatment and protein tannin aggregation and sensory attributes of green tea infusion was reported by Ferrara et al. (2001). Many elements present in food at major, minor and trace levels are reported to be essential to man's wellbeing. Human body requires both metallic and non-metallic elements for healthy growth, development and proper functioning of the body. The determination of these elements in beverages, water, food, plant and soil is thus of utmost importance and is currently the subject of studies by various researchers (Saud and Al-Oud, 2003, WHO, 1998a, b). It is in view of the above that this research was set up with the aim of determining the proximate, caffeine and tannin analyses in some brands of tea consumed in Kano metropolis with the objective of providing data on the nutritious status of each brand in order to assist consumers to decide on the best tea brand to consume. 


\section{MATERIALS AND METHODS}

All the solvents and reagents used were of Analar grade, distilled water was used as solvent for solution preparation and all glassware were washed, cleaned and dried in an oven at $105^{\circ} \mathrm{C}$.

\section{Sample Collection}

The samples of dried tea leaves commonly consumed in Kano metropolis were obtained from Dala Food Nigeria Ltd (India and Srilanka samples) and Kano central market (China, Kenya and Mambilla samples).

\section{Sample Treatment}

The dry tea leaves $(100 \mathrm{~g})$ were crushed using pestle and mortar, and later sieved repeatedly to pass through a $2 \mathrm{~mm}$ sieve. The powder was stored at room temperature in dry air-tight container for analysis.

\section{Procedures}

Moisture content for each tea sample was determined using an oven set at $105^{\circ} \mathrm{C}$ and dried to constant weight (AOAC, 1984). Total ash was determined using Muffle furnace set at $550^{\circ} \mathrm{C}$ for 4 hrs (AOAC, 1984), crude fibre was determined using fibre cap 2021/2023 system, the system involves weighing, defatting, hot extraction and filtration, final defecting, drying, weighing the ash and calculation (ACCA, 2002). Ether extract content in the samples was determined using soxhlet extraction method (AOAC, 1984). Total nitrogen was analyzed using Kjeldhal digestion method followed by distillation and titration. Caffeine was determined by boiling $5 \mathrm{~g}$ of the tea sample, filtered, washed with chloroform, evaporated, dried in an oven and weighed as outlined by the Kjeidhal method (AOAC, 1984). Tannin content was determined by titrimetric method (Kirk - Othmer, 1995).

\section{RESULTS AND DISCUSSION}

The results of the proximate composition of tea sample (Camellia sinensis) are presented in Table 1. The mean moisture content of all the tea samples was $6.8 \%$, ranged from $5.6-7.5 \%$ with Mambila and Srilanka tea having the lowest contents of 5.6 and $6.5 \%$ respectively and coefficient of variation $15.31 \%$. India tea has the highest moisture content of $7.5 \%$. High moisture content aids microbial activities, oxidation - reduction processes and fungal growth. The variation in the moisture may be attributed to the degree of drying type and nature of tea involved (Kumar et al., 2005).

The ash content of a sample is an indication of its mineral content, it does not necessarily indicate high quality except when there is a favorable balance of the essential minerals (Ahmed et al., 1989). The results of the ash content analysis are as shown in Table 1 with mean distribution of $6.3 \%$ ranged from $4.9 \%-7.2 \%$ and coefficient of variation $23.8 \%$, Kenya and Mambila samples contained the highest ash content of $7.2 \%$ while Srilanka had the lowest ash content of $4.9 \%$. This is within the limit recommend for tea sample (Ahmed et al., 1989). This high ash content suggests that it is a good source of minerals. The crude fiber content analysis results are shown in Table 1, which follows the order Srilanka >Mambilla> India >Kenya> China with a mean of $15.80 \%$, ranging from $14.00-18.82 \%$ and coefficient of variation $48.4 \%$. Srilanka tea had the highest crude fibre content of $18.82 \%$ which is in agreement with Okanlawon (2000).Crude fibre stimulates the movement of the bowel and helps to prevent constipation (Okanlawon, 2000). Ether extract contents results are shown in Table 1 with a mean of $10.16 \%$ range of $9.3 \%-10.6 \%$ and coefficient of variation $10.4 \%$ of all the tea samples analysed, Mambila tea had the highest content with $10.6 \%$ while Kenya tea had the lowest, $9.3 \%$ which is low when compared with the results of Okanlawon (2000).

Total nitrogen contents for these tea samples are as shown in Table 1, with mean distribution of 1.43 , range of $0.88 \%$ in Kenya sample to $1.75 \%$ in Srilanka and Mambila and coefficient of variation $7.5 \%$. The variation may probably be due to variation in organic matter contents of these samples, as appreciable amount of nitrogen in tea samples occurs in organic form. The results obtained for the total nitrogen compares favourably with the value reported by Sahito et al. (1998) for Chinese tea.

The caffeine content in tea leaves samples analysed varied from $1.40 \%$ in Kenya sample to $2.80 \%$ in China sample, with a mean of $1.83 \%$ and coefficient of variation 11.6 percent (Table 2), It is within the acceptable range (Ferrara et al., 2001).Caffeine is a stimulant, that is commonly found in many foods and drinks that we consume. Caffeine has a mildly addictive effect in the body, the active ingredient that makes tea and coffee valuable to human, the ability to put off sleep and an increased capacity for thinking (Donald and Gary, 1990).

The results of tannin content in Table 2 showed that China tea had the least value of tannin content of $6.00 \%$ while Kenya tea had the highest value of tannin content of $8.50 \%$. with mean distribution of $7.44 \%$ and coefficient of variation 18.7 percent, which is low when compared with the results of Donald and Gary (1990).Tannins have traditionally been considered anti-nutritional but it is now known that their beneficial or anti-nutritional properties depend upon their chemical structure and dosage. If ingested in excessive quantities, tannins inhibit the absorption of minerals, such as iron which may, if prolonged, lead to anemia. It is advised to drink tea and coffee between meals, foods rich in vitamin C help neutralize tannin effects on iron absorption. Adding lemon juice to tea will reduce the negative effect of tannins in iron absorption as well. However adding milk to coffee and tea has very little to no influence on the inhibitory effect to tannin (Dommgang et al., 1998). 
Table 1: Proximate Compositions of Tea Samples Analyzed (\%)*

\begin{tabular}{lccccc}
\hline Sample & Moisture content & Ash content & Crude fibre content & Ether extract & Total nitrogen \\
\hline China & 7.2 & 7.1 & 14.00 & 10.10 & 1.56 \\
Kenya & 7.2 & 7.2 & 14.02 & 9.30 & 0.88 \\
India & 7.5 & 5.1 & 14.10 & 10.30 & 1.23 \\
Srilanka & 6.5 & 4.9 & 18.82 & 10.50 & 1.75 \\
Mambila & 5.6 & 7.2 & 18.04 & 10.60 & 1.75 \\
Mean & 6.8 & 6.3 & 15.79 & 10.16 & 1.43 \\
SD & 0.766 & 2.119 & 2.421 & 0.518 & 0.376 \\
CV & 0.153 & 0.238 & 0.484 & 0.104 & 0.075 \\
\hline
\end{tabular}

*The values are mean of three replicate measurements

Table 2: Results of Caffeine and Tannins Content (\%)*

\begin{tabular}{lcc}
\hline Sample & Caffeine content & Tannin content \\
\hline China & 2.80 & 6.00 \\
Kenya & 1.40 & 7.74 \\
India & 1.90 & 7.80 \\
Srilanka & 1.42 & 8.50 \\
Mambila & 1.63 & 7.18 \\
Mean & 1.83 & 7.444 \\
SD & 0.579 & 0.933 \\
CV & 0.116 & 0.187 \\
\hline
\end{tabular}

*The values are mean of three replicate measurements

\section{CONCLUSION}

The results of this study on tea brands selected from the Kano central market and Dala foods show that the tea samples have considerable contents of the

\section{REFERENCES}

Ahmed, I, S.S.H Zaidi and Z.A. Khan, (1989). The determination of major, minor and trace elements in tea, tea liquor, instant coffee and cocoa samples. Pak. J.Sci Ind. Res., 32 (8): 513-515.

ACCA, ISO, AACC and AOCS (2002). The determination of crude fibre in food. Standard using the Fibrecap 2021/2023.

AOAC (1984), Official method of analysis of the association of official analytical chemists (AOAC) $14^{\text {th }}$ edition. Washington, D.C.USAP Pp.152-162.

Donald, L. P. and Gary, M. L. (1990). Introduction to organic laboratory techniques western Washington University, Rellinghan Washington. Pp. 72-77

Dommgang, F. Eka, O.U. and Fokou, H. (1998). Nutrient composition of some leafy vegetable eaten in Cameroun (1): evaluation of sugars, crude fat, mineral and oxalic acid. Nigerian Journal of Nutritional Sciences, 19(2):97 104.

Ferrara, L., Montesano, D. and Senatore, A. (2001). The distribution of minerals and flavonoid in tea plant. Fermaco 56:397 - 401.

Han, W.Y., Liang, Y.R., Yang, Y.J., Ma, L.F. and Ruan, J.Y. (2006). Effect of processing on the $\mathrm{Pb}$ and $\mathrm{Cu}$ pollution of tea in Chinese. J. Tea Sci. 26: 95-101.

Karimi G, Hasanzadeh M. K, Nili A, Khashayarmanesh Z , Samiei Z, Nazari F, Teimuri M (2008). parameters studied. The levels of these parameters were within the acceptable daily intake from air, food and water.

Concentrations and Health Risk of Heavy Metals in Tea Samples Marketed in IRAN Pharmacologyonline 3: 164-174

Kirk- Othmer, (1995). Encyclopedia of chemical Technology. $4^{\text {th }}$ Edn. A Wiley- nescience publication, John Wiley and Sons. Vol, 23.

Kumar, A., Nair, A. G. C., Reddly, A.V.R. and Garg, A.N. (2005). Availability of essential elements in India and US tea brands. Food Chem., 89: 441-448.

Okanlawon, O. S. (2000). Post Harvest Handling of Grains. Nigerian Stored products research in Institute Kano.Pp.12

Sahito S.R , Kazi, T.G. Jakharani, M.A., Kazi, G. H., Shar, Q.G. and Shaikh, S. (2005) The contents of fifteen essential, trace and toxic elements in some green tea samples and in their infusion. Tour. Chem. Soc. Pak. 27(1):43-47.

Saud, S. and AL-Oud, H. (2003). Heavy metal contents in tea and herb leaves. Pak. J. Bio1. Sci., 6: 208-212.

WHO, (1998a), Guidelines for Drinking Water Quality. $2^{\text {nd }}$ Edn. Health criteria and Other Supporting Information. World Health organization, Geneva, pp: 47-61. Web search WHO guidelines for drinking water quality.

WHO, (1998b), Guidelines for Drinking Water quality. $2^{\text {nd }}$ Edn. Health Criteria and Other Supporting Information, World Health Organization, Geneva, pp: 308-313. Web search WHO guidelines for drinking water quality. 